\title{
OS ASPECTOS QUE COMPÕEM O CONCEITO DE IMAGEM CORPORAL PELA ÓTICA DO ADOLESCENTE
}

\section{THE ASPECTS THAT COMPOSES THE BODY IMAGE'S CONSTRUCT BY THE ADOLESCENT'S VIEW}

Maria Aparecida Conti *

Conti MA. Os Aspectos que Compõem o Conceito de Imagem Corporal pela Ótica do Adolescente. Rev Bras Crescimento Desenvolvimento Hum. 2008; 18(3): 240-253

\section{Resumo:}

O objetivo deste estudo é identificar os construtos do conceito imagem corporal presentes nos discursos dos adolescentes e relacioná-los à produção nacional. Para tanto, desenvolveu-se um estudo exploratório transversal com adolescentes, em uma instituição particular de ensino do ABC paulista. Aplicou-se uma entrevista semi-estruturada, utilizando-se a técnica do Discurso do Sujeito Coletivo, embasada no conceito das Representações Sociais. A tabulação dos dados ocorreu por meio da utilização de três figuras metodológicas: idéia central, expressões-chave e o Discurso do Sujeito Coletivo. Nos depoimentos de 121 jovens, foram registradas 200 expressões-chave que foram agrupadas em seis idéias centrais: 1) aspecto afetivo (31,5\%); 2) aspecto cognitivo (29,5\%); 3) aspecto descritivo (20,5 \%); 4) “normal” (9,0 \%); 5) aspecto comportamental (8,50 \%) e 6) dependente da situação (1,0 \%). Conclui-se pelos Discursos do Sujeito Coletivo que o conceito de imagem corporal é multidimensional, apresentando-se de forma equilibrada quanto aos aspectos afetivo, cognitivo e descritivo. Em pesquisas envolvendo o tema imagem corporal, é necessário esclarecer qual o aspecto a ser avaliado, para assim optar-se pelo melhor instrumento.

Palavras-chave: Imagem corporal; pesquisa qualitativa; adolescência; representação social.

Estudo baseado na Tese de Doutorado intitulada: A imagem corporal de adolescentes: validação e reprodutibilidade de instrumentos. Apoio CNPq: Processo: 140097/2005-8

* Doutora em Saúde Pública. Especialista em Psicologia Clínica. Pesquisadora do AMBULIM - Instituto de Psiquiatria da Faculdade de Medicina/USP

Correspondência para: Maria Aparecida Conti. AMBULIM - Instituto de Psiquiatria da Faculdade de Medicina - USP. Rua: Dr. Ovídio Pires de Campos, 785, 2 andar. São Paulo - 05403-010.São Paulo, SP - Brasil. Fone/fax: 11- 3069-6975 / 4229 5180. E-mail: maconti@usp.br 


\begin{abstract}
:
The aim of this study was to recognize the construct of the body image in the young's discourse and to relate them it the national researches. For that an explorer cross-section study was carried out with adolescents of a private school in SP, ABC Paulista. Semistructured interview were applied using The Discourse of the Collective Subject' technique based in the Social Representation' concept. Data were tabulated using three methodological approaches: central idea; key expressions and discourse of the collective subjective. Discourses of 121 adolescents was evaluated, 200 key expressions was grouped in six central idea: 1) affective aspect (31.5\%); 2) cognitive aspect (29.5\%); 3) descriptive aspect (20.5\%); 4) normal (9.0\%); 5) behavior aspect (8.5\%) and 6) depends on the situation (1.0\%). The study concluded by the Discourse of the Collective Subject that the body image construct seemed to be multidimensional, presenting itself of form balanced between the aspects affective, cognitive and descriptive. In researches involving the construct "body image" is necessary to have clearly which the aspect will be evaluate for then choose the best instrument.
\end{abstract}

Key words: Body image; qualitative research; adolescence; social representations.

\section{INTRODUÇÃO}

A imagem corporal refere-se a um construto complexo e multifacetário que envolve, no mínimo, aspectos perceptuais, afetivos, cognitivos e comportamentais das experiências corporais. ${ }^{1}$ Schilder ${ }^{2}$ define-a como uma imagem do corpo formada na mente do indivíduo, ou seja, o modo como o corpo apresenta-se para este indivíduo, envolvido pelas sensações e experiências imediatas.

Banfield e $\mathrm{McCabe}^{3}$ exploram este tema e avaliam a imagem corporal sob três fatores: afeto e cognição referentes ao corpo, percepção da imagem corporal e importância corporal e comportamentos alimentares. Para as autoras, a dimensão afetiva refere-se aos sentimentos pessoais envolvendo a aparência corporal e o aspecto cognitivo, aos pensamentos e crenças sobre esta aparência e tamanho corporal. Os aspectos perceptivos relacionamse à exatidão no julgamento do indivíduo quanto ao seu tamanho, formato e peso corporal em relação a sua apresentação atual. Por fim, o aspecto comportamental que diz respeito às atitudes voltadas para a corporeidade.
Das fases do desenvolvimento humano, talvez a adolescência seja a mais significativa para a estruturação da imagem corporal. Para Osório ${ }^{4}$, na adolescência, o indivíduo conquista a imagem corporal definitiva, como também a estruturação final de sua personalidade. A adolescência configura-se como um período de passagem para a fase adulta, caracterizando-se pelas mudanças e adaptações das capacidades no âmbito produtivo e reprodutivo. ${ }^{5}$ Este período normalmente inicia-se com a manifestação dos primeiros sinais da puberdade e abrange também importantes mudanças psicológicas e sociais. ${ }^{6}$ Os adolescentes representam $19 \%$ da população mundial 7 ; no Brasil, tem-se 20,8\% de jovens (10 a 24 anos); já no Estado de São Paulo, este valor é de $17,7 \% .^{8,9}$

O campo de estudo e pesquisa relacionados à imagem corporal data do início do século passado. Cash e Pruzinsky ${ }^{1}$ descrevem quatro fases no decorrer deste período. A primeira fase caracterizou-se pelo esforço clínico em compreender as formas de neuropatologias das experiências corporais. $\mathrm{O}$ 
foco da segunda foram as experiências corporais nas distorções perceptivas, induzidas por lesões cerebrais. A terceira fase caracterizouse pelos estudos sob a perspectiva psicoanalítica e psicodinâmica. Já na última fase, foi proposta uma teoria integrativa, relacionando informações de várias áreas da psicologia experimental, considerando a experiência corporal como multidimensional.

No cenário brasileiro, as pesquisas relacionadas à imagem corporal iniciaram-se na década de 90. Um dos estudos precursores foi o desenvolvido por Cordás e Castilho ${ }^{10}$ que apresentaram uma versão do Questionário de Imagem Corporal (Body Shape Questionnaire$B S Q)^{11}$ para o português, com o intuito de se avaliar a insatisfação corporal de pacientes com transtornos alimentares. A partir de então, diversas pesquisas têm sido realizadas sobre o tema, podendo ser classificadas de acordo com seus objetivos. Estes variam entre aspectos relacionados: às questões conceituais, para a compreensão das bases teóricas ${ }^{12-16}$; à avaliação de populações específicas, mensurando-se a imagem corporal destes grupos com diversos instrumentos ${ }^{17-27}$; e estudos de validade e reprodutibilidade de métodos, para adequação dos instrumentos aplicados. ${ }^{28-31}$

A respeito dos estudos que avaliam a imagem corporal, observa-se a aplicação de inúmeros instrumentos que mensuram aspectos específicos do construto "imagem corporal”. Atualmente, há no mínimo cinqüenta medidas disponíveis para esta avaliação. ${ }^{32}$ Os instrumentos mais usados em estudos populacionais são os questionários e as escalas de silhueta, devido à sua praticidade de aplicação e correção. ${ }^{33}$

Nas pesquisas nacionais, o instrumento mais aplicado é o BSQ.17,19,25,27 Este fornece uma avaliação contínua e descritiva das insatisfações da imagem corporal em populações clínicas e não clínicas. Trata-se de um questionário de 34 itens de auto-preenchimento na forma de escala Likert de pontos, com o obje- tivo de mensurar a preocupação com a forma e peso corporais nas últimas quatro semanas, especialmente a freqüência com que indivíduos com e sem transtornos alimentares experimentam a sensação de se "sentirem gordo (a)s". Para Ghaderi e Scott, ${ }^{34}$ o BSQ avalia o aspecto afetivo da imagem corporal.

As escalas de silhuetas, também amplamente utilizadas para avaliação da imagem corporal, se caracterizam pelos desenhos de figuras humanas. Por meio deste instrumento, o sujeito escolhe, em uma série que varia do mais magro ao mais gordo, a imagem que mais se aproxima de como se percebe e outra aquela que se aproxima de como gostaria de ser. ${ }^{20,24-}$ 26,28,30 Desta forma, são identificadas informações acerca da insatisfação em relação à imagem corporal, sendo esta entendida como o valor da diferença entre o corpo real (percebido) e o ideal (desejado). Outro instrumento ainda aplicado são as escalas de áreas corporais ${ }^{22,23}$, que apresentam diversas áreas corporais; o sujeito deve avaliar, em uma escala Likert de pontos, seu grau de satisfação, que varia da plena insatisfação à plena satisfação. ${ }^{32}$

Por fim, a técnica do desenho da figura humana ${ }^{18}$ corresponde a uma avaliação de exatidão perceptiva do indivíduo. Questões como tamanho, formato, aspecto apresentado e peso relatados são avaliados em relação à apresentação atual do sujeito. Nesta técnica, solicitase inicialmente ao entrevistado para que desenhe uma figura humana; em seguida, é realizada uma nova solicitação para que faça um novo desenho, agora de outro sexo. Acredita-se que este instrumento explora em profundidade os aspectos afetivos e cognitivos do construto imagem corporal.

Considerando as várias possibilidades de medidas para avaliação da imagem corporal, alguns cuidados são necessários para que o pesquisador não incorra em erros que inviabilizem seu estudo. ${ }^{35}$ A seleção cuidadosa do instrumento no estudo é indispensável para que sejam identificadas as informa- 
ções almejadas. Além disso, é de extrema importância a definição, a priori, dos aspectos a serem avaliados nos estudos relacionados à imagem corporal. As pesquisas relacionadas a este aspecto abordam a multidimensionalidade deste construto, possibilitando o acesso a numerosas informações. Deve-se considerar ainda que este tema é relativamente novo na área científica e há pouco conhecimento, em especial no cenário brasileiro.

Nesse sentido, a presente pesquisa caracteriza-se por ser exploratória, sinalizando e salientando este cuidado metodológico necessário para a caracterização do conceito de imagem corporal. Desta forma, o objetivo é identificar no discurso dos jovens os aspectos seriam revelados, as proporções e sua relação com os estudos nacionais.

\section{MÉTODO}

Este estudo foi realizado em uma instituição da rede particular de ensino no ABC paulista, em São Bernardo do Campo - SP, com jovens do Ensino Fundamental I e Fundamental II, regularmente matriculados, na faixa etária de 10 a 18 anos de idade.

\section{Participantes}

A amostra selecionada foi intencional $^{36,37}$, correspondendo a 121 adolescentes. Todos os jovens que participaram da pesquisa de Doutorado (386 jovens) foram convidados a participar e aqueles que se disponibilizaram foram entrevistados individualmente. A participação foi voluntária e a coleta de dados ocorreu em dezembro de 2006 em uma sala restrita, disponibilizada pela direção escolar.

\section{Procedimento}

Antecedendo a trabalho de campo, em setembro de 2006, foi realizado um pré-teste com 4 adolescentes, de ambos os sexos, na faixa etária de 13 anos, da mesma instituição. Pode-se confirmar a compreensão do procedimento, o que implicou na manutenção do mesmo.

Aplicou-se a técnica da entrevista semiestruturada, individualmente, com a gravação em fita magnética. Ao início da entrevista, foi solicitado ao jovem que fechasse os olhos e que formasse uma imagem acerca de seu corpo. Após esta sensibilização, foi solicitado ao adolescente que respondesse à seguinte pergunta: "Como percebe esta imagem criada sobre você? Fale um pouco disto”. A duração das entrevistas variou de 3 a 7 minutos.

As entrevistas foram transcritas em um editor de texto e relidas em sua íntegra. Para análise do conteúdo discursivo, utilizou-se a técnica de análise do Discurso do Sujeito Coletivo (DSC), que consiste em utilizar um instrumento de tabulação e organização dos dados qualitativos com a aplicação das figuras metodológicas: "expressões-chave”; "idéias centrais" e o "Discurso do Sujeito Coletivo" (DSC). ${ }^{38}$

Esta técnica embasa-se no conceito das Representações Sociais, como uma forma de expressar diretamente a representação social de um dado sujeito social. Para tanto, agrega-se em um discurso-síntese os conteúdos discursivos de sentido semelhante emitido por pessoas distintas. ${ }^{39}$ Assim, cada indivíduo entrevistado contribui com sua cota de fragmento de pensamento para o pensamento coletivo. Para a elaboração dos DSC, utilizou-se o programa Qualiquantisoft, versão 1.3C.

A pesquisa foi desenvolvida de acordo com a Resolução 196/96 do Conselho Nacional de Saúde e aprovada pelo Comitê de Ética da Faculdade de Saúde Pública da Universidade de São Paulo (Protocolo de Pesquisa: 1377). Os pais e/ou responsáveis dos adolescentes participantes deste estudo assinaram um Termo de Consentimento Livre e Esclarecido. 


\section{RESULTADOS}

Participaram do estudo 121 jovens, sendo 76 destes do sexo feminino e 45 jovens do sexo masculino, na faixa etária de 11 a 18 anos, com a idade média de 13,8 anos (desvio padrão = 2,1 anos), cursando da quinta série (Ensino Fundamental I) ao terceiro ano colegial (Ensino Fundamental II).

Das respostas, extraíram-se 200 expressões-chave que foram agrupadas em seis idéias centrais: 1) aspecto afetivo" (31,5 \%); 2) aspecto cognitivo (29,5\%); 3) aspecto descritivo (20,5\%); 4) "normal” (9,0 \%); 5) aspecto comportamental (8,5\%) e 6) dependente da situação (1,0 \%). As freqüências dos discursos ficaram equilibradas entre os aspectos afetivos (31,5\%), cognitivos (29,5\%); e descritivo (29,5 \%).

Na Tabela 1, observam-se as idéias centrais e trechos dos DSC que identificaram o aspecto afetivo na construção do conceito da imagem corporal. Foi utilizado como critério para tabulação e organização dos conteúdos discursivos a seleção de palavras como "gosto", "satisfeito”, “gosto de algumas partes” e "não gosto” para o respectivo agrupamento.

Apresentam-se na Tabela 2 as idéias centrais e os discursos com representações sociais que identificam o aspecto cognitivo na elaboração do conceito da imagem corporal. Palavras como “imagino”, “acho”, “considero" e "penso” foram utilizadas para

\section{Tabela 1: Idéia Central, freqüência da resposta e o Discurso do Sujeito Coletivo dos adolescentes em relação ao aspecto afetivo. São Bernardo do Campo, 2006}

\begin{tabular}{|c|c|}
\hline $\begin{array}{l}\text { Idéia Central } \\
\text { Aspecto Afetivo } \\
\qquad(31,5 \%)\end{array}$ & Discurso do Sujeito Coletivo \\
\hline “Gosto” & $\begin{array}{l}\text { "Tô satisfeito com o meu corpo, gosto do meu cabelo, do meu rosto, } \\
\text { do meu peso, da minha bunda também. Gosto do jeito que eu sou e } \\
\text { de mim, do meu corpo. Tenho uns defeitos, mas eu não ligo assim”. }\end{array}$ \\
\hline $\begin{array}{c}\text { "Gosto de algumas } \\
\text { partes" }\end{array}$ & $\begin{array}{l}\text { "Gosto de algumas partes e outras não. Não gosto muito de algumas } \\
\text { gordurinhas, assim que têm no abdômen, no quadril e o meu } \\
\text { problema mesmo é barriga. Às vezes eu não gosto muito de andar } \\
\text { de saia porque tenho as canelas finas e por ter estrias... “. }\end{array}$ \\
\hline “Não gosto” & $\begin{array}{l}\text { "Eu não estou satisfeito (a), não gosto do que eu vejo, não gosto } \\
\text { muito de mim. Tem umas partes que eu não gosto. Não gosto muito } \\
\text { do meu peito, da minha coxa, do rosto, das minhas pernas, meus } \\
\text { braços, tórax, meu rosto, do meu cabelo, do meu nariz, do pé. Tenho } \\
\text { um problema muito grande com a minha barriga. Tenho umas } \\
\text { gordurinhas que não são muito agradáveis. Fico com aquela coisa } \\
\text { assim apavorado (a) que eu tô muito gordo (a), tô muito gordo (a) e } \\
\text { não gosto muito do meu físico e corpo, é meio desproporcional. Me } \\
\text { incomoda só assim, sabe essas coisas, aqui ó, molinha. Eu queria } \\
\text { ser mais forte, ter braços e pernas mais definidos." }\end{array}$ \\
\hline
\end{tabular}


Tabela 2: Idéia Central, freqüência da resposta e o Discurso do Sujeito Coletivo dos adolescentes em relação ao aspecto cognitivo. São Bernardo do Campo, 2006

\begin{tabular}{|c|c|}
\hline $\begin{array}{l}\text { Idéia Central } \\
\text { Aspecto Cognitivo } \\
(29,5 \%)\end{array}$ & Discurso do Sujeito Coletivo \\
\hline "Imagino" & $\begin{array}{l}\text { "Eu me imaginei em frente ao espelho, tipo eu refletindo no espelho, } \\
\text { fui pegando todos os detalhes, vendo tudo, o corpo por completo, } \\
\text { desde a perna. Eu vi o que eu acho de mim e o que eu vejo no } \\
\text { espelho eu acho bom". }\end{array}$ \\
\hline "Acho" & $\begin{array}{l}\text { “Acho que eu tenho até um corpo legal, acho atraente, tipo assim } \\
\text { com a minha idade e tudo, me vi bonito (a). Eu me considero, tipo } \\
\text { saudável, não magro nem gordo. Acho que estou satisfeito (a) com } \\
\text { meu corpo, porque não é nem tão magro (a), como aquelas obcecadas, } \\
\text { e nem gordo (a)”. }\end{array}$ \\
\hline "Acho" & $\begin{array}{l}\text { Só acho que minhas orelhas podiam ser um pouquinho mais pra } \\
\text { trás, não sei, é meio desproporcional, tenho a canela muito fina e as } \\
\text { coxas são mais grossas”. }\end{array}$ \\
\hline "Acho" & $\begin{array}{l}\text { “O meu corpo assim magrinho, eu sou magro (a), bom, pro meu } \\
\text { tamanho assim, eu me acho um pouquinho magro (a) demais". }\end{array}$ \\
\hline “Acho” & $\begin{array}{l}\text { "Pra idade eu acho que eu tô um pouco acima do peso, mas não } \\
\text { tanto. Me acho um pouquinho gordo(a), com a perna também gorda, } \\
\text { um pouquinho fora do peso. Tem hora que quando eu coloco uma } \\
\text { roupa assim justa, me acho muito gordo (a), tenho que tirar na hora } \\
\text { e colocar uma mais larga assim”. }\end{array}$ \\
\hline “Considero” & $\begin{array}{l}\text { "Me considero uma pessoa nem gorda, nem muito magra, um pessoa } \\
\text { intermediária, eu não sou muito alta, sou pequena e tô na altura } \\
\text { normal”. }\end{array}$ \\
\hline “Acho" & $\begin{array}{l}\text { “Às vezes, assim, me acho bonita e tal, mas às vezes eu me acho } \\
\text { muito magra, acho que vai evoluindo de acordo com cada pessoa, } \\
\text { cada um tem um jeito, ninguém é igual.... às vezes meu corpo é } \\
\text { bonito, às vezes, não”. }\end{array}$ \\
\hline “Acho" & $\begin{array}{l}\text { “Acho que eu sou bonita assim, mas não sei se todas as pessoas } \\
\text { acham assim. Você fica às vezes imaginando: será que sou eu que tô } \\
\text { errado (a)? Será que não é nada disso? Alguma coisinha que eu } \\
\text { como assim, às vezes eu fico pensando muito nisso, muito na forma } \\
\text { do meu corpo e tal e fico com aquela neura” . }\end{array}$ \\
\hline
\end{tabular}

a tabulação e organização dos conteúdos discursivos.

A Tabela 3 apresenta as idéias centrais e trechos dos DSC que identificam o aspecto descritivo na construção do conceito da imagem corporal. Palavras como "percebo" e a descrição em si das partes corporais foram utilizadas para a tabulação e 
Tabela 3: Idéia Central, freqüência da resposta e o Discurso do Sujeito Coletivo dos adolescentes em relação ao aspecto descritivo. São Bernardo do Campo, 2006

\section{Idéia Central \\ Aspecto descritivo \\ Trechos do Discurso do Sujeito Coletivo \\ $(29,5 \%)$}

Meninos "Percebo de mim mesmo assim, um corpo sem muito músculo, magro, um menino saudável, alto e pequeno em relação aos ombros, aos braços. Não sou tão gordo, nem tão magro e meu peso tá mais ou menos na proporção da minha altura... Sou loiro, olho verde, meu nariz eu acho que é normal.”

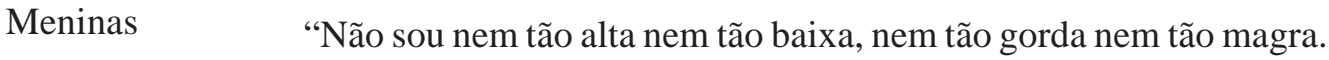
Sou alta, morena, cabelo longo. Sou bem magra, as minhas pernas são bem finas, pequena, cabelo comprido, nariz pequeno, só que batatinha, os dentes amarelos, lábio rachado, olhos claros, braços peludos, tenho os braços longos, pernas longas, finas, cabelos pretos. Sou baixinha e um pouco gordinha, os olhos puxados, minhas pernas são um pouquinho grossas. Sou mais ou menos alta, eu tenho coxas largas, tenho olhos verdes e ainda tô me desenvolvendo. O nariz é um pouquinho grande, meu braço é gordinho e é muito grande. $\mathrm{O}$ peito é muito grande pra idade e a barriga é um pouco grande pra mim. Percebo que tô gorda e tenho muitas estrias, no braço na cintura e perna”.

“normal” "Essa imagem parece normal, como as outras que eu vejo pela rua, normal, eu sou uma pessoa comum como qualquer outra. Vi o meu corpo assim, normal, me enxerguei normalmente”.

organização dos conteúdos discursivos. Somente para este item há a descrição segundo o sexo devido às significativas diferenças observadas.
Observam-se, na Tabela 4, as idéias centrais e os discursos com representações sociais que expressam os conteúdos que identificam o aspecto comportamental na elaboração da imagem cor- 
Tabela 4: Idéia Central, freqüência da resposta e o Discurso do Sujeito Coletivo dos adolescentes em relação ao aspecto comportamental. São Bernardo do Campo, 2006

Idéia Central

Aspecto

comportamental

$(8,5 \%)$

\section{Discurso do Sujeito Coletivo}

"Fazer regime"

“Tenho necessidade de trabalhar um pouquinho fisicamente, mas aí a preguiça é maior, então não dá, se eu pudesse mudar alguma coisa no meu corpo eu mudaria só a minha barriga mesmo. Sempre quis assim, tentar emagrecer, mas às vezes eu relaxo, às vezes eu consigo. Precisaria fazer regime, alguma coisa. Eu até pedi pro meu pai pra deixar eu ir pra academia”.

“Usar medicação” “Um dos pontos assim que eu precisaria é uma medicação assim, pra usar no meu rosto. Que, tipo, o meu rosto assim que eu queria mais limpo assim.”

"Me cuidar bastante" “Sempre procurei me cuidar bastante, esporte, alimentação, tudo”.

“Não me preocupo” “Não tenho muita preocupação quanto a minha forma, se tô gordo ou tô magro. Não procuro muito fazer regime e tal porque pra mim tá tudo bom, é um peso legal.... Aí eu tento engordar só que eu nunca consigo, aí eu já até desisti porque eu tento, tento, tento e eu não consigo engordar, aí eu desisto”.

poral. Frases como "tenho necessidade de trabalhar fisicamente”, "tentar emagrecer” e "procurei me cuidar” foram utilizadas para a tabulação e organização dos conteúdos discursivos.
Na Tabela 5, registram-se as idéias centrais e os discursos com representações sociais que expressam os conteúdos que identificam o aspecto "normal” e “dependente da 
situação” na elaboração da imagem corporal. O aspecto "normal” (9,0 \%) foi tabulado em separado devido à constante citação por parte dos adolescentes; no entanto, complementa a idéia central do aspecto descritivo.

Tabela 5: Idéia Central, freqüência da resposta e o Discurso do Sujeito Coletivo dos adolescentes em relação ao aspecto dependente da situação. São Bernardo do Campo, 2006

Idéia Central

Aspecto social

$(1,0 \%)$

\section{Discurso do Sujeito Coletivo}

"A imagem que eu vejo de mim tem vezes que muda a minha forma

"Dependente da situação" de pensar. Tem hora que eu olho assim no espelho, eu me acho bem, mas tem hora que eu olho e acho muito assim, nossa, tô parecendo uma obesa, depende da situação”.

\section{DISCUSSÃO}

A aplicação da Teoria das Representações Sociais como estratégia metodológica possibilita o resgate das imagens construídas acerca do real, com a sua manifestação realizada por meio da linguagem, dos sentimentos e das próprias condutas. ${ }^{37}$ No caso do presente estudo, o grupo identificou alguns conceitos que envolvem o tema "imagem corporal", o que pôde ser confirmado pelos pressupostos teóricos já existentes. ${ }^{3,1}$

Para Oliveira e Roazzi ${ }^{40}$, a elaboração das representações sociais se dá na fronteira entre o social e psicológico, nos processos das trocas sociais, sendo estas capazes de estabelecer conexões entre as abstrações do saber e das crenças e o aspecto concreto do dia-a-dia do sujeito, em suas trocas com o meio. Perminte-se assim articular os aspectos objetivos e concretos da vida com os aspectos simbólicos.

Na técnica do DSC, fragmentos dos discursos individuais são agrupados, dando corpo ao final, em um único discurso, uma síntese, que se compõe no DSC, como representação social do grupo estudado, sendo esta a expressão das crenças, opiniões e valores do mes- mo. ${ }^{38,39}$ No discurso dos jovens, os aspectos centrais que compuseram o conceito "imagem corporal” foram claramente descritos. Houve um equilíbrio entre três destes: o afetivo, o cognitivo e descritivo (perceptivo).

Os estudos nacionais publicados até então com enfoque no tema da imagem corporal exploram o grau de satisfação corporal, sendo este avaliado como aspecto afetivo do construto “imagem corporal”. Para tanto, há a aplicação de algumas técnicas distintas de mensuração. Isto pode ser observado nas pesquisas desenvolvidas por Conti et al. ${ }^{22,23}$, em que foi aplicada uma escala de áreas corporais, e no estudo de Pinheiro e Giugliani ${ }^{26}$, em que foi utilizada uma escala de silhueta. Nos dois primeiros estudos, constatou-se que a insatisfação estava relacionada ao sexo feminino, ao excesso de peso e à maturação sexual; e já no terceiro, que $82 \%$ de jovens entrevistados estavam insatisfeitos com sua imagem corporal, $55 \%$ almejavam ter um corpo mais magro e $28 \%$ desejavam ter um corpo maior, para meninas e meninos, respectivamente.

No discurso dos jovens foi possível registrar uma oscilação entre gostar, gostar de algumas partes e não gostar do corpo, 
correspondendo a 31,5 \% das idéias centrais. A satisfação corporal e os fatores relacionados à mesma, como sexo, idade, estado nutricional, entre outros, ainda não foram completamente explorados, com alguns pesquisadores pontuando a necessidade de uma maior atenção a estes aspectos. ${ }^{1}$ Sabe-se que meninas revelam uma maior insatisfação, com preferência por corpos magros e esguios. Já meninos mostram sua insatisfação revelando a preferência por corpos grandes e musculosos. ${ }^{34}$ Pela perspectiva sociocultural, segundo Jackson ${ }^{41}$, é possível compreender esta diferença, pois meninos e meninas recebem diferentes estímulos culturais e sociais, os quais influenciam diretamente em valores $\mathrm{e}$ comportamentos individuais.

$\mathrm{O}$ aspecto cognitivo foi registrado em 29,5 \% das idéias centrais no discurso dos jovens. Mesmo pesquisando uma população distinta do presente estudo, Almeida et al. ${ }^{18}$, com a aplicação da técnica do desenho da figura humana, pesquisaram a auto-imagem de 30 mulheres com obesidade mórbida e de $30 \mathrm{mu}$ lheres não obesas. Constataram que as obesas apresentavam dificuldades em expressar, simbolicamente, sua vivência corporal, sugerindo a presença de indicadores de inferioridade, deslocamento e preocupação com o corpo e a beleza.

Vale ressaltar que o limiar que separa um aspecto do outro, como por exemplo o afetivo e o cognitivo, em relação ao conceito imagem corporal é muito tênue. Isto pode ser observado no discurso dos jovens, que julgam seu sentimento; ou seja, utilizam a função cognitiva para avaliar o seu sentimento em relação ao corpo. Como saída, os pesquisadores priorizam alguns construtos, dando ênfase aos objetivos do seu estudo.

Em relação aos aspectos perceptivos, foi observado que as meninas mostraram-se mais detalhistas em relação ao sexo masculino. A estimação do tamanho e forma corporais segundo o sexo é um dos aspectos mais explora- dos nos estudos de imagem corporal, provavelmente, pela fácil aplicação e correção de instrumentos que mensuram esta dimensão.

Pesquisas como a de Damasceno et al. ${ }^{20}$ e Branco et al. ${ }^{25}$ confirmam esta idéia. No primeiro estudo, utilizando a escala de silhuetas de Stunkard ${ }^{42,43}$, constataram que $24,4 \%$ das mulheres e $18 \%$ dos homens referiram satisfação com o corpo, e que os homens expressaram maior desejo em ter um corpo mais forte e volumoso, com baixo percentual de gordura. Para as mulheres, o tipo físico ideal é um corpo magro e menos volumoso. Já no segundo estudo, adotando o mesmo instrumento para avaliação, os pesquisadores relacionaram o estado nutricional com a percepção e satisfação da imagem corporal de 1.009 adolescentes, de ambos os sexos. Verificaram que a insatisfação com a imagem corporal foi mais prevalente entre os adolescentes com sobrepeso e obesidade, com destaque para as meninas. Concluíram que os meninos tendem a aceitar a sua imagem corporal, independentemente do estado nutricional, e as meninas demonstram maior preocupação com a imagem corporal, motivo este responsável pela manutenção de um padrão eutrófico.

Da mesma forma, Veggi et al..$^{21}$ avaliaram a percepção do peso, o Î́ndice de Massa Corporal (IMC) e transtornos mentais comuns entre 4.030 funcionários adultos de ambos os sexos de uma universidade no Rio de Janeiro. Para avaliar a percepção de peso, os autores basearam-se na auto-percepção do peso corporal, por meio da classificação em cinco categorias: muito acima do ideal, um pouco acima do ideal, ideal, um pouco abaixo do ideal ou muito abaixo do ideal e concluíram que a percepção inadequada do peso corporal, independentemente do IMC, estava associada à presença dos transtornos mentais, como sentimentos de tensão, depressão, incapacidade de lidar com situações habituais, ansiedade e falta de confiança, comuns nas mulheres, mas não nos homens. 
Almeida et al. ${ }^{24}$ investigaram a percepção do tamanho e formas corporais de 150 mulheres da cidade de Ribeirão Preto-SP, aplicando a escala de silhuetas de Stunkard. ${ }^{42}$ Independentemente do estado nutricional, as escolhas dos tamanhos normais e ideais foram associadas às representações de baixo peso. Concluiu-se que as diferenças entre a adequação da percepção real e ideal são relevantes, pois, sinalizam a direção das dificuldades expressas pela população pesquisada, relativas à auto-percepção corporal.

O aspecto comportamental correspondeu a 8,5 \% das idéias centrais. Idéias como "fazer regime”, "usar medicação” e "me cuidar bastante” fazem parte do repertório vivencial destes jovens. Mesmo com populações distintas, é possível observar na literatura relatos do quanto a atitude em relação à imagem corporal se faz presente. Lemes et al. ${ }^{17}$ entrevistaram adultos obesos e com sobrepeso, de ambos os sexos, em um Spa médico no interior de São Paulo, por meio do BSQ ${ }^{11}$, e observaram alterações graves da imagem corporal, mesmo com pesos adequados para o grupo feminino. Já com atletas adultas femininas, com a aplicação do BSQ ${ }^{11}$, Oliveira et al. ${ }^{40}$ constataram que $33 \%$ das jovens apresentaram leve distorção da imagem corporal, mesmo estando com os valores de gordura corporal dentro dos padrões esperados para a idade e sexo.

A pesquisa de Kakeshita e Almeida ${ }^{27}$ avaliou a relação entre o IMC e a percepção da auto-imagem com 106 estudantes universitários por meio de uma escala de silhuetas desenvolvida pelos próprios autores, segundo diferentes métodos psicométricos (escolha, limiar absoluto e visual analógico) e o BSQ. ${ }^{11}$ Os autores concluíram que tanto homens como mulheres apresentaram distorção na autopercepção da imagem corporal, subestimando-a (mulheres obesas e homens, independentemente do estado nutricional) ou superes- timando-a (mulheres eutróficas ou com sobrepeso), sugerindo insatisfação com a imagem corporal, considerando o desejo de ter corpos mais magros.

Interessante observar que o aspecto social foi identificado nos discursos analisados neste estudo. Ou seja, para os jovens, dependendo da situação há um tipo de percepção corporal. Este discurso correspondeu a 1\% das idéias centrais, e trata-se de um aspecto ainda não foi explorado em pesquisas nacionais.

Em suma, observou-se nos discursos dos jovens um equilíbrio entre os aspectos afetivo, cognitivo e perceptivo. Em relação aos estudos nacionais, a maior freqüência deu-se para os aspectos afetivo e perceptivo, com a aplicação de questionários, escalas de silhuetas e de áreas corporais.

Cabe salientar que a presente pesquisa avaliou o discurso de uma única população sob a perspectiva do método qualitativa, implicando em algumas limitações. A principal delas diz respeito a um único olhar em relação ao tema pesquisado. Sendo assim, pode-se identificar os construtos que compõem o conceito "imagem corporal” e sua freqüência; no entanto, são necessários estudos com populações distintas, envolvendo diferentes faixas etárias e circunstâncias, como indivíduos com transtornos alimentares, obesidade e limitações físicas.

Foi possível reafirmar, por meio dos discursos construídos dos adolescentes, a multidimensionalidade do conceito "imagem corporal". Para os jovens, os aspectos perceptivos, afetivos, cognitivos e sociais compõem o conceito “imagem corporal”. Por ser uma nova área em construção mais estudos são necessários para se conhecer com maior propriedade os aspectos teóricos que envolvem o tema, bem como os fatores a ele relacionados, como por exemplo, os diferentes estilos de vida, prática esportiva, qualidade dos relacionamentos interpessoais, qualidade dos relacionamentos familiares, entre outros mais. 


\section{REFERÊNCIAS}

1. Cash TF, Pruzinsky T (orgs). Body Image: a handbook of theory, research, and clinical practive. New York: Guilford Press; 2002.

2. Schilder P. A Imagem do corpo - As energias construtivas da psique. São Paulo: Martins Fontes; 1981.

3. Banfield SS, McCabe MP. An evaluation of the construct of body image. Adolescence 2002;37(146):373-393.

4. Osório LC. Adolescente hoje. $3^{\mathrm{a}}$ ed. Porto Alegre: Artes Médicas; 1992.

5. Kanauth RK, Gonçalves H. Juventude na era da Aids: entre o prazer e o risco. In: Almeida MIM, Eugenio F. (orgs). Culturas Jovens - novos mapas do afeto. Rio de Janeiro: Jorge Zahar Ed; 2006. p.92-120.

6. (WHO). World Health Organization. Nutrition in adolescence: issues and challenges for the health sector: issues in adolescence health and development. Genova: WHO; 2005.

7. (WHO). World Health Organization. Controling the global obesity epidemic. Genova: WHO;2003.

8. Instituto Brasileiro de Geografia e Estatística (IBGE ). Brasil em Síntese. Relatório do censo demográfico da população brasileira. [acesso em 24 abr 2006]. Disponível em http:// www.ibge.gov.br/brasil_em_sintese/ default.htm.

9. Fundação SEADE. Produtos: Análise Demográfica - 2002. Disponível em "URL: http://www.Seade.gov.br/ produtos/anuario/2002/dem/dem 2002_01.htm” [2004 abr 6]

10. Cordás TA, Castilho S. Imagem corporal nos transtornos alimentares instrumentos de avaliação: "Body Shape Questionnaire”. Psiquiatria Biológica 1994; 2(1):17-21.
11. Cooper PJ, Taylor M, Cooper Z, Fairburn CG. The development and validation of the Body Shape Questionnaire. International Journal of Eating Disorders 1987; 6:485-94.

12. Claudino AM, Borges MBF. Critérios diagnósticos para os transtornos alimentares: conceitos em evolução. Revista Brasileira de Psiquiatria 2002; 24(Supl III):7-12.

13. Freitas S, Gorenstein C, Appolinario JC. Instrumentos para avaliação dos transtornos alimentares. Revista Brasileira de Psiquiatria 2002; 24 (Supl III):34-8.

14. Saikali CJ, Soubhia CS, Scalfar BM, Cordás TA. Imagem corporal nos transtornos alimentares. Revista de Psiquiatria Clínica 2004;31(4):164-166.

15. Barros DD. Imagem corporal: a descoberta de si mesmo. História, Ciência, Saúde 2005;12(2):547-554.

16. Giordani RCF. A auto-imagem corporal na anorexia nervosa: uma abordagem sociologia. Psicologia \& Sociedade 2006;18(2):81-88.

17. Lemes SO, Valverde MA, Fisberg, Perez IP, Franques AM. Percepção de imagem corporal em adultos (obesos e sobrepeso) do "Spa Médico São Pedro/ Sorocaba-SP”. A Folha Medica 2001;4(120):229-234.

18. Almeida GAN, Loureiro SR, Santos JE. A imagem corporal de mulheres morbidamente obesas avaliadas através do desenho da figura humana. Psicologia Reflexão e Crítica 2002;5(2):283-292.

19. Oliveira FP, Bosi MLM, Vigário OS, Vieira RS. Comportamento alimentar e imagem corporal em atletas. Revista Brasileira de Medicina e Esporte 2003;9(6):348-356.

20. Damasceno VO, Lima JRP, Vianna JM, Vianna VR, Novaes JS. Tipo físico ideal e satisfação com a imagem corporal de 
praticantes de caminhada. Revista Brasileira de Medicina e Esporte 2005;3(1):181-186.

21. Veggi AB, Lopes CL, Faerstein E, Schieri R. Índice de massa corporal, percepção do peso corporal e transtornos mentais comuns entre funcionários de uma universidade no Rio de Janeiro. Revista Brasileira de Psiquiatria 2004;26(4):242-247.

22. Conti MA., Frutuoso MF, Gambardella AMD. Excesso de peso e insatisfação corporal em adolescentes. Revista de Nutrição - Puc/Campinas 2005;18(4):491-497.

23. Conti MA, Gambardella AMD, Frutuoso MF. Insatisfação com a imagem corporal em adolescentes e sua relação com a maturação sexual. Rev Bras Cresc Desenv Hum 2005;15(2):36-44.

24. Almeida GAN, Santos JE, Pasian SR, Loureiro SR. Percepção do tamanho e forma corporal de mulheres: estudo exploratório. Psicologia em Estudo 2005;10(1):27-35.

25. Branco LM, Hilária MOE, Cintra IP. Percepção e satisfação corporal em adolescentes e a relação com seu estado nutricional. Revista de Psiquiatria Clínica 2006; 33(6):292-296.

26. Pinheiro AP, Giugliani ERJ. Body dissatisfaction in brazilian schoolchildren: prevalence and associated factors. Revista de Saúde Pública 2006;40(3):489-496.

27. Kakeshita IS, Almeida SS. Relação entre índice de massa corporal e a percepção da auto-imagem em universitários. Revista de Saúde Pública 2006;40(3):497-504.

28. Scagliusi FB, Alvarenga $M$, Polacow V, Cordás TA, Queiroz GKO, Coelho D, Philippi ST, Lancha Jr AH. Psychometric Testing and applications of the Body Attitudes Questionnaire translated into
Portuguese. Perceptual and Motor Skills 2005;101:25-41.

29. Nunes MA, Camey S, Olinto MTA, Mari JJ. The validity and 4-year test-retest reliability of the Brazilian version of the Eating Attitudes Test-26. Brazilian Journal of Medical and Biological Research 2005;38:1655-1662.

30. Scagliusi FB, Alvarenga M, Polacow V, Cordás TA, Queiroz GKO, Coelho D, Philippi ST, Lancha Jr AH. Concurrent and discriminant validity of the Stunkard's figure rating scale adapted into Portuguese. Appetite 2006; 47:77-82.

31. Galindo EMC, Carvalho AMP. Tradução, adaptação e avaliação da consistência interna do Eating Behaviours and Body Image Test para uso com crianças do sexo feminino. Revista de Nutrição 2007;20(1):47-54.

32. Thompson MA, Gray JJ. Development and validation of a new body-image assessment scale. Journal of Pearsonality Assessment 1995;64(2):258-269.

33. Mendelson BK, McLaren L, Gauvin L, Steiger $\mathrm{H}$. The relationship of selfesteem and body esteem in women with and without eating disorders. International Journal of Eating Disorders 2002;31(3):318-23.

34. Ghaderi A, Scott B. The reliability and validity of the Swedish version of the Body Shape Questionnaire. Scandinavian Journal of Psychology 2004;45:319-324.

35. Thompson JK. The (mis)measurement of body image: ten strategies to improve assessment for applied and research purposes. Body Image 2004;1:7-14.

36. Pereira MG. Epidemiologia Teoria e Prática. Rio de Janeiro: Editora Guanabara Koogan; 1999.

37. Minayo MCS. O desafio do conhecimento - Pesquisa qualitativa em 
saúde. 8. Edição. São Paulo: Hucitec; 2004.

38. Lefèvre F, Lefèvre AMC, Teixeira JJV. (Orgs). O discurso do sujeito coletivo: uma nova abordagem metodológica em pesquisa qualitativa. Caxias do Sul: EDUCS; 2000.

39. Lefèvre F, Lefèvre AMC. O pensamento coletivo como soma qualitativa. http:// hygea.fsp.usp.br/quali-saude/soma (acesso em 28/06/2007).

40. Oliveira AB, Roazzi A. A representação social da "Doença dos Nervos" entre os gêneros. Psicologia: Teoria e Pesquisa 2007;23(1): 91-102.

41. Jackson LA. Physical attractiveness -A social perspective. In: Cash, T.F. \&
Pruzinsky T (orgs). Body Image: a handbook of theory, research, and clinical practive. New York: Guilford Press; 2002.p13-21.

42. Stunkard A, Sorensen T, Schlusinger F. Use of Danish adoption register for the study of obesity and thinness. In: Kety S, Rowland LP, Sidman RL, Matthysse SW. The genetics of neurological and psychiatric disorders. New York: Raven;1983.

43. Madrigal-Fritsch H, Irala-Estevez J, Martinez-Gonzales MA, Kearney J, Gibney M, Martinez-Hernandez JA. Percepción de la imagem corporal como aprocimación qualitativa al estado nutricional. Salud Publica de México 1999;41:479-486.

Recebido em: 26/07/2008

Modificado em: 28/08/2008 Aceito em: 25/11/2008 